\title{
Computed Tomography Analysis of the Anterosuperior Portion of the Bulla Lamella in Chinese Subjects and Its Surgical Significance in Endoscopic Frontal Sinusotomy
}

\author{
Muhan Shi ${ }^{\mathrm{a}}$ Yuxiao Wu ${ }^{\mathrm{a}}$ Yuguang Wang ${ }^{\mathrm{a}}$ Min Wang ${ }^{\mathrm{a}}$ Fei Yuan ${ }^{\mathrm{b}}$ \\ Zhimin Xing ${ }^{\text {a }}$ Hui Li ${ }^{\text {a }}$ Shien Huanga \\ aDepartment of Otorhinolaryngology Head and Neck Surgery, Peking University People's Hospital, Beijing, China; \\ ${ }^{b}$ Department of Radiology, Peking University People's Hospital, Beijing, China
}

\section{Keywords}

Bulla lamella - Chronic rhinosinusitis - Supra bulla frontal cell · Supraorbital ethmoid cell · Frontal sinus drainage pathway

\begin{abstract}
Introduction: The anterosuperior portion of the bulla lamella can extend into the frontal sinus and form the supra bulla frontal cell (SBFC) and supraorbital ethmoid cell (SOEC). This can affect the frontal drainage pathway and make surgery more challenging. Objectives: The aim of the study was to compare the anatomical characteristics of SBFC and SOEC in Chinese chronic rhinosinusitis (CRS) patients and explore the relationship between the cells and frontal sinusitis (FS). The surgical skills in dealing with these cells were also studied. Methods: We prospectively identified SBFC and SOEC in 114 patients with CRS by computed tomography (CT). The sides of the patients were divided into groups $A$ (with FS) and $B$ (without FS). CT scans were analyzed to distinguish the SBFC, SOEC, and the drainage pathway. Statistical analysis was conducted to determine whether the cells were associated with the occurrence of FS. Results: The prevalence of frontal cells was as follows: SBFC: $9.65 \%$, SOEC: $21.93 \%$. There was an association between the presence of SBFC and FS $(p<$
\end{abstract}

0.05). The anterior drainage pathway was present in patients with SBFC and SOEC, anterolateral pathway in those with SBFC/SOEC coexisting with the frontal septal cell, and anteromedial pathway in those with SBFC/SOEC coexisting with the supra agger frontal cell. Conclusions: There was an association between the presence of SBFC and the occurrence of FS. Extension of the anterosuperior portion of the bulla lamella into the frontal sinus obstructed the drainage pathway posteriorly. Understanding the anatomy may help surgeons thoroughly dissect the bulla lamella.

(c) 2021 The Author(s)

Published by S. Karger AG, Basel

\section{Introduction}

Chronic rhinosinusitis (CRS) is one of the most common nasal diseases. It is associated with many factors such as microbial dysbiosis, genetic factors, anatomical variations, and allergy [1]. Anatomical variations, particularly the complex frontal recess, are a known risk factor of CRS and have been a major research topic [2-5]. The International Frontal Sinus Anatomy Classification

Muhan Shi, Yuxiao Wu, and Yuguang Wang contributed equally to this paper.
(C) 2021 The Author(s)

Published by S. Karger AG, Basel

This is an Open Access article licensed under the Creative Commons Attribution-NonCommercial-4.0 International License (CC BY-NC) (http://www.karger.com/Services/OpenAccessLicense), applicable to the online version of the article only. Usage and distribution for commercial purposes requires written permission.
Correspondence to:

Min Wang, minwang333@ sina.com 
(IFAC) published in 2016 [6] emphasized not only the location and number of the cells but also the influence of the cells on the frontal sinus drainage pathway. This system provides surgeons with an accurate nomenclature for cells based on their positions and helps surgeons have a better understanding of the frontal sinus. Frontal recess cells have been classified into 3 groups, namely, anterior, posterior, and medial, which affect the drainage pathway anteriorly, posteriorly, and medially, respectively. According to the IFAC, the supra bulla frontal cell (SBFC) originates from the supra bulla region and pneumatizes along the skull base in the posterior region of the frontal sinus. The supraorbital ethmoid cell (SOEC) is defined as an anterior ethmoid cell that pneumatizes around, anterior to, or posterior to the anterior ethmoid artery over the roof of the orbit [6]. Embryologically, the drainage pathway of the frontal sinus is between the first lamella and the second lamella (bulla lamella). Both SBFCs and SOECs are derived from the second lamella [7]. These can extend into the frontal sinus and may obstruct the frontal ostium posteriorly. However, the features and differences in anatomy of SBFC and SOEC have been underestimated and rarely mentioned in reports. The purpose of this study was to explore the anatomical and clinical significance of the anterosuperior portion of the bulla lamella extending into the frontal sinus, that is, the SBFC and SOEC. The fontal sinus drainage pathway related to these cells was also examined.

\section{Material and Methods}

This prospective study was conducted from January 2017 to January 2018 in our hospital. 114 patients were included in the study. Left and right sides were considered individually. The inclusion criteria were age $>18$ years; diagnosis of CRS, prior frontal septal cell (CT) scan, failed medical management; and agreement to undergo endoscopic sinus surgery (ESS). Exclusion criteria included age younger than 18 years, other countries, sinonasal tumor, previous surgery, and sinus fracture. The scans were performed on a GE LightSpeed CT scanner (GE Medical Systems, Milwaukee, WI, USA) with $0.625-\mathrm{mm}$-thick axial cuts and the intermediate window width and level settings of the CT scan were 2,000 and 200 Hounsfield units, respectively. The coronal and parasagittal CT scan images were reconstructed on a computer workstation.

As all sides had CRS, we divided them into 2 groups based on whether the side had frontal sinusitis (FS). Group A included sides with FS and Group B comprised sides free from FS. Although it is mentioned in the IFAC that SOEC can share a partition with the frontal sinus, this has not been elaborated. It is essential to determine whether the cell enters the frontal sinus. We followed Wormald's suggestion to look first at the parasagittal scan, that is, take the narrowest point between the frontal beak and the skull base, is the frontal ostium. If the cell migrates past that point then it extends into the
Table 1. Demographic characteristics of patients included in this study

\begin{tabular}{llll}
\hline Variable & FS - & FS + & Total \\
\hline $\begin{array}{llll}\text { Age, years (mean } \pm \text { SD) } \\
\text { Gender, } n(\%)\end{array}$ & $48.77 \pm 13.74$ & $48.41 \pm 14.18$ & $48.68 \pm 13.78$ \\
$\quad$ Male & & & \\
$\quad$ Female & $14(51.9)$ & $59(67.8)$ & $73(64.0)$ \\
$\begin{array}{l}\text { Side, } n \text { (\%) } \\
\quad \text { Unilateral } \\
\text { Bilateral }\end{array}$ & $13(48.1)$ & $28(32.8)$ & $41(36.0)$ \\
& $35(56.5)$ & $35(45.5)$ & $35(30.7)$ \\
& $27(43.5)$ & $52(67.5)$ & $79(69.3)$ \\
\hline
\end{tabular}

FS, frontal sinusitis.

Table 2. Prevalence of different frontal cells

\begin{tabular}{llll}
\hline Cell type & FS,$- n(\%)$ & FS,$+ n(\%)$ & Total, $n(\%)$ \\
\hline SBFC & $2(0.88)$ & $20(8.77)$ & $22(9.65)$ \\
SOEC & $19(8.34)$ & $31(13.59)$ & $50(21.93)$ \\
Ssb\&so & $68(29.82)$ & $88(38.60)$ & $156(68.42)$ \\
Total & $89(39.04)$ & $139(60.96)$ & $228(100)$
\end{tabular}

SOEC, supraorbital ethmoid cell; SBFC, supra bulla frontal cell; FS, frontal sinusitis.

Table 3. Statistical analysis of different frontal cells in FS development

\begin{tabular}{llllll}
\hline Comparison group & $n$ & df & $E$ & $x^{2}$ & $\begin{array}{l}p \text { value } \\
(2 \text {-sided) }\end{array}$ \\
\hline SBFC-SOEC-Ssb\&so & 228 & 2 & 8.59 & 9.672 & 0.008 \\
SBFC-SOEC & 71 & 1 & 6.42 & 6.180 & 0.013 \\
SBFC-Ssb\&so & 178 & 1 & 8.65 & 9.617 & 0.002 \\
SOEC-Ssb\&so & 205 & 1 & 20.56 & 0.720 & 0.396 \\
\hline
\end{tabular}

SOEC, supraorbital ethmoid cell; SBFC, supra bulla frontal cell; FS, frontal sinusitis.

frontal sinus. The CT scans were carefully analyzed in the axial, coronal, and sagittal positions by 3 rhinologists and a radiologist using Centricity Universal Viewer (Centricity Universal Viewer; GE Healthcare, Chicago, IL, USA) to distinguish SBFC and SOEC types I and II and to look for the frontal sinus drainage pathway. In cases that had coexisting frontal septal cell (FSC) and supra agger frontal cell (SAFC), all these cells were analyzed simultaneously. Patients with FS had undergone frontal sinusotomy after enrollment, and the cells were further verified by surgery. The partitioning $\chi^{2}$ method was used for statistical analysis to determine whether the cells were associated with the occurrence of FS by comparing the SBFC group, SOEC group, and the group without both the cells (Ssb\&so, Sine both SBFC and SOEC). When $p$ values (2-sided) were $\leq 0.05$, the re- 


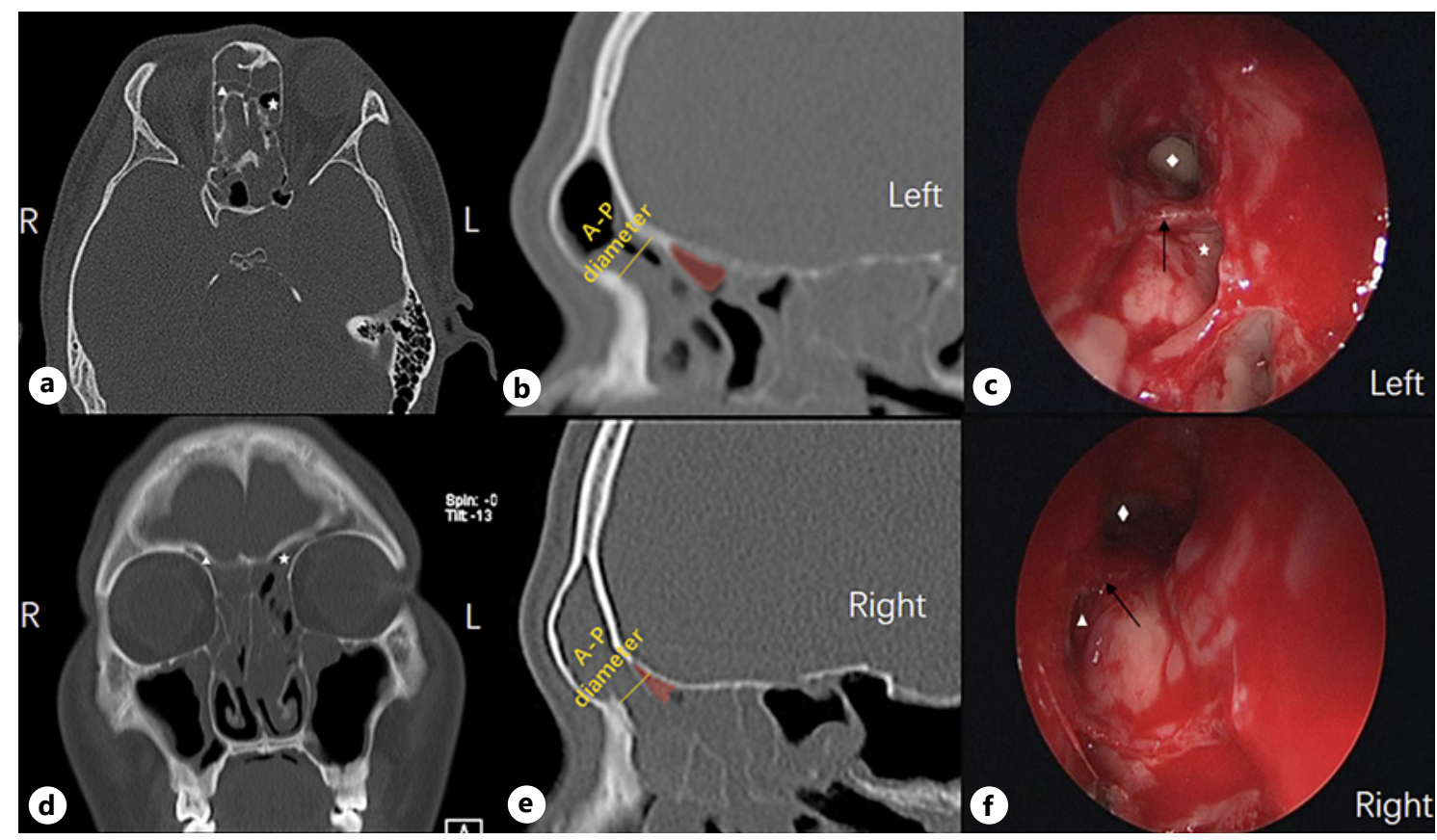

Fig. 1. a, b, d, e CT scans of different types of SOECs. b Parasagittal CT scan of the SOEC which pneumatizes over the orbit but does not enter the frontal sinus. e Parasagittal CT scan of the SOEC which pneumatizes over the orbit, and a small portion passes through the frontal ostium. c, $\mathbf{f}$ Endoscopic images of different types of SOECs. c Endoscopic image of SOEC does not enter the frontal sinus. $\mathbf{f}$ Endoscopic image of SOEC enters frontal sinus. $\downarrow$, SOEC does not enter the frontal sinus; $\Delta$, SOEC enters the frontal sinus; $\diamond$, frontal ostium; $\rightarrow$, residual second lamella. With bilateral anterior drainage pathway, because the pneumatization of both the SOECs was not very good, the drainage pathway was not very narrow. SOEC, supraorbital ethmoid cell; CT, computed tomography.

sults were considered statistically significant. Because the comparative samples were divided into 3 groups, we used the Bonferroni correction to revise the test level. All statistical analyses were performed using SPSS 22.0 (SPSS; IBM Corp., Armonk, NY, USA).

\section{Results}

A total of 228 sides of frontal sinus CT scans of 114 CRS patients were analyzed. The demographic characteristics of the patients are shown in Table 1. The prevalence of frontal cells was as follows: SBFC: $9.65 \%$, SOEC: $21.93 \%$ (Table 2). In terms of the relationship between frontal cells and FS, there were statistical differences among the 3 groups, so we compared the groups in pairs (Table 3). Because the standard test level a was 0.05, the revised test level $\alpha^{\prime}$ was 0.0167 . Comparison of $p$ values of each pair with $\alpha^{\prime}$ shows that the $p$ values of SBFC-SOEC and SBFCSsb\&so were $<0.0167$, which means the SBFC group was different from SOEC group and others without SBFC or SOEC. Thus, there was a statistically significant associa- tion between the presence of SBFC and the occurrence of FS. However, the $p$ value of SOEC-Ssb\&so was $>0.0167$, so the relationship between SOEC and FS was not significant.

In terms of the frontal sinus drainage pathway, we mainly recorded the cells that enter the frontal sinus and obstruct the pathway around the frontal recess. Because some SOECs did not enter the frontal sinus, they were not included in the discussion. The frontal sinus drainage pathway was anterior to the cell in patients only with SBFC or SOEC (Fig. 1, 2). When SBFC or SOEC was present along with SAFC, the drainage pathway ran posterior to the SAFC and anteromedial to SBFC/SOEC (Fig. 3). When SBFC or SOEC coexisted with FSC, the drainage pathway was lateral to the FSC and anterolateral to SBFC/SOEC. Only one case had 3 groups of cells and the drainage pathway is lateral to FSC, posterior to SAFC and anterolateral to SBFC/SOEC. All frontal sinusotomy procedures were successfully performed endoscopically. 


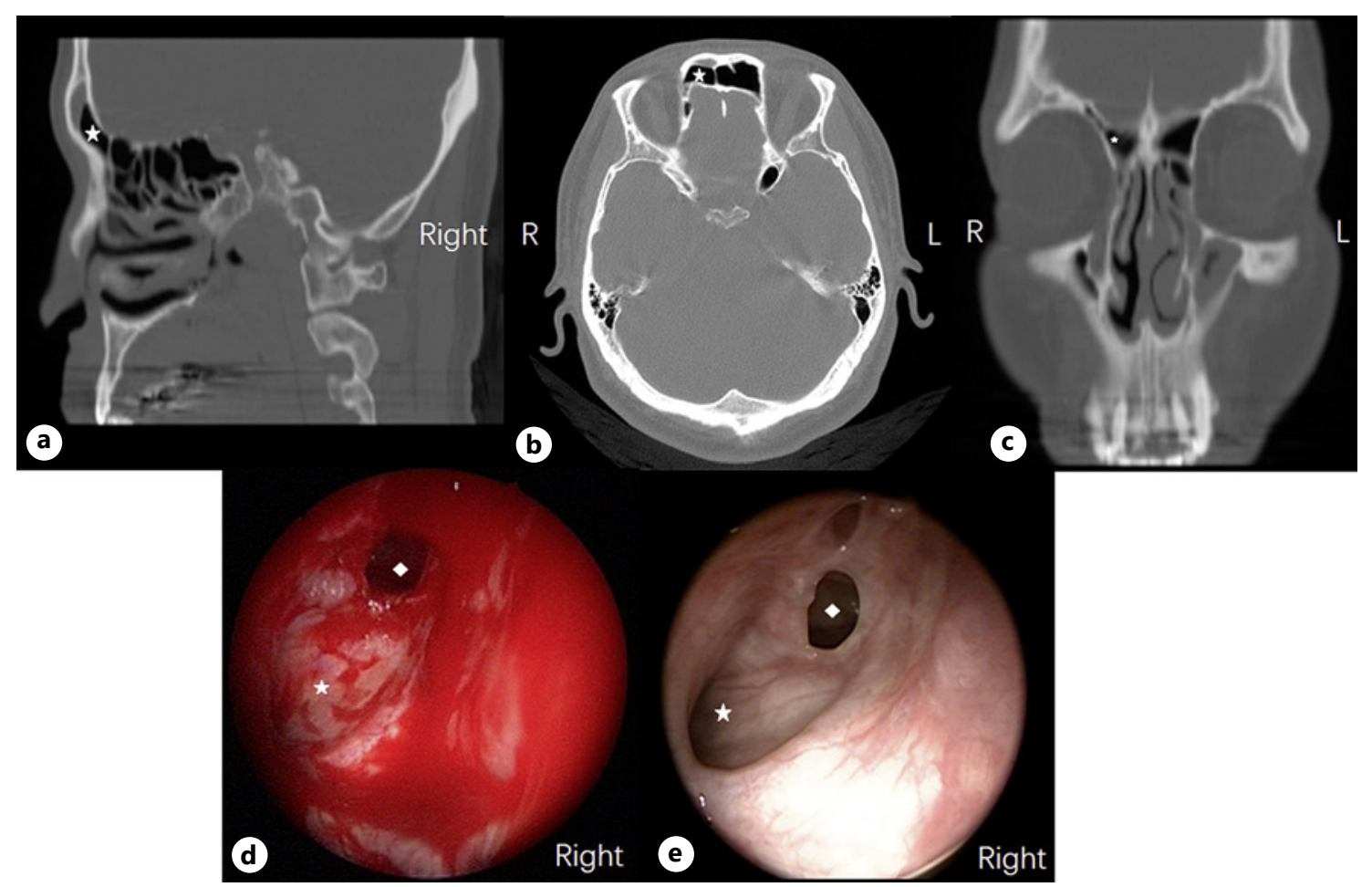

Fig. 2. CT scans of a supra bulla frontal cell (SBFC) (a-c). Endoscopic images of SBFC (d, e). Intraoperative picture (d); postoperative picture (e). $\diamond$, frontal ostium; $\downarrow$, supra bulla frontal cell. The cell pneumatizes along the skull base into the frontal sinus. It obstructs the frontal ostium and pushes the drainage pathway anteriorly.CT, computed tomography; SBFC, supra bulla frontal cell.

\section{Discussion}

Both Kuhn and IFAC classified the frontal cells into 3 groups $[6,8,9]$. The anterior cell group has been well studied and analyzed in many papers [10-12]. In terms of the medial group, Wang et al. [2] have studied the anatomy of the intersinus spetal cell (ISSC, i.e., FSC) and its impact on endoscopic surgery. For the posterior group, a few studies addressed the anatomy of the SOEC $[13,14]$ and studies on SBFCs have mainly focused on its clinical significance $[4,5]$ However, a detailed comparison of the anatomical structure and clinical significance of the SBFC and SOEC has not been reported to date.

This study has determined that the prevalence of SBFC did not significantly differ from that observed in previous studies (Table 4) [4, 8, 15-17]. The results of our study were most consistent with another study involving Chinese patients by Han et al. [16]. However, the prevalence of SOEC in these studies widely varies. The prevalence in Caucasians was as high as 64.6\%, while that in East Asians was much lower. The prevalence of SOEC in our study was significantly higher than that in other East Asian countries, which may be due to ethnic differences between Chinese and other East Asian populations. There were also some other differences between the results of our study and those of the others involving Chinese subjects. This might have been because our study selected CRS patients, while their samples involved healthy subjects. In addition, in terms of selection criteria, we strictly followed the IFAC and classified cells that pneumatized over the roof of the orbit, even a little, as SOEC, which may have led to a decrease in the number of the SBFCs and an increase in the number of the SOECs.

To obtain reliable results, it is important to understand the accurate definition of SBFC, SOEC, and SBC. Both SBFC and SOEC are the well pneumatized bulla. When the bulla develops anteriorly along the skull base into the frontal sinus, it forms the SBFC, but when the bulla pneumatizes laterally above the orbit SOEC appears. Both SBFC and SOEC can enter into frontal sinus and obstruct the drainage pathway. Sometimes it is not very easy to differentiate these 2 cells. According to the definition of the SBFC, no part of the SBFC can be located above the orbit. According to our understanding, the differences between 


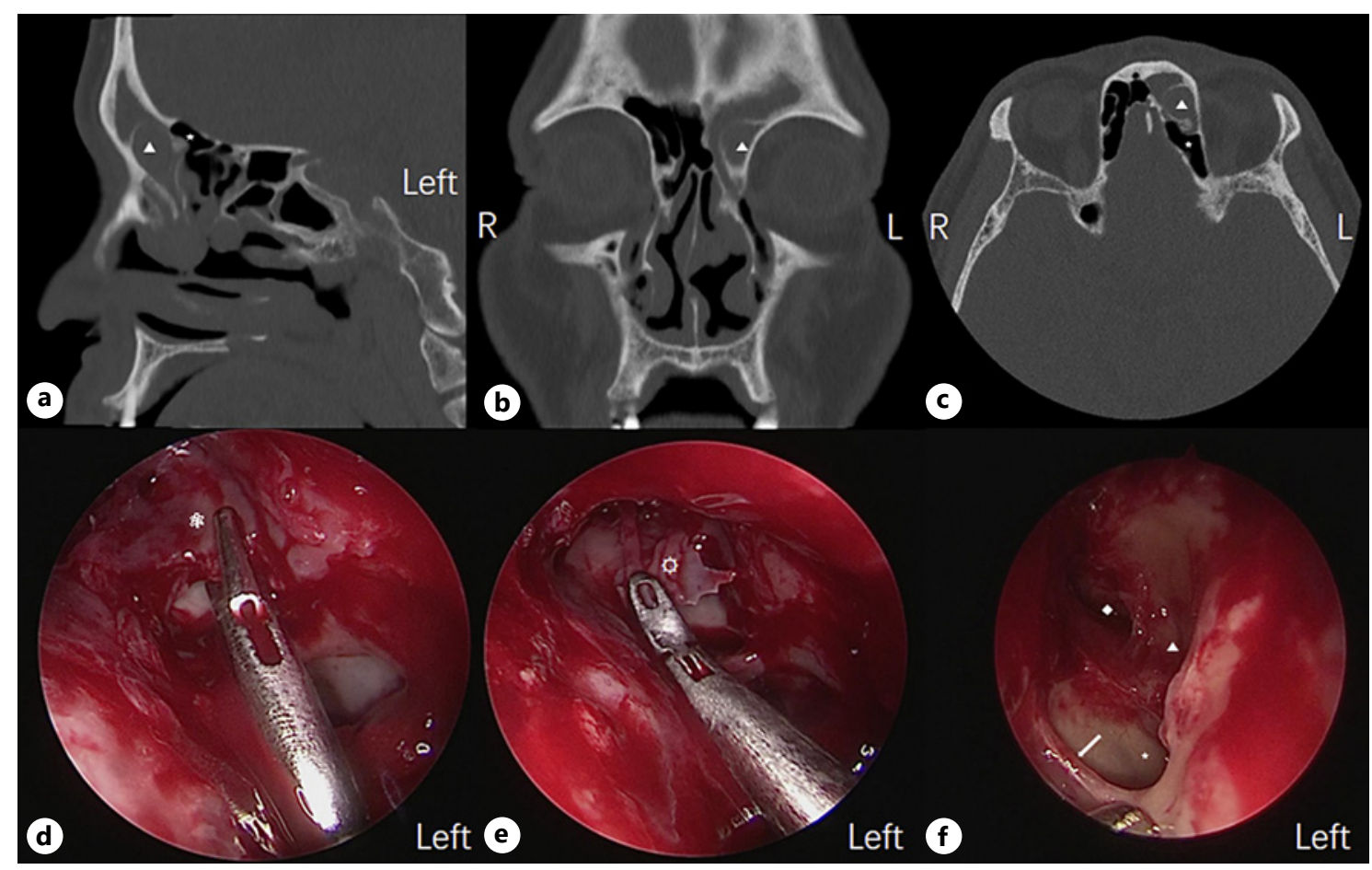

Fig. 3. a-c CT scans of a SOEC coexisting with a SAFC. $\triangle$, SAFC; 2 , SOEC. The frontal drainage pathway is squeezed by the SAFC medially and SOEC anteriorly. $\mathbf{d - f}$ Endoscopic pictures of opening the frontal sinus. Removing the second lamella $(\mathbf{d})$; $*$, second lamella; removing the first lamella (e); first lamella; frontal recess area after Draf II A (f); $\diamond$, frontal ostium; $\Delta$, SAFC; $\downarrow$, SOEC; $\rightarrow$, residual first lamella; $\rightarrow$, residual second lamella; $\Rightarrow$, anterior ethmoid artery; SAFC, supra agger frontal cell; SOEC, supraorbital ethmoid cell; CT, computed tomography.

Table 4. Comparison of prevalence of SBFC and SOEC in various populations

\begin{tabular}{lllllll}
\hline Cell type & $\begin{array}{l}\text { Our study, } \\
228 \text { sides }\end{array}$ & $\begin{array}{l}\text { Japanese, } \\
\text { 300 sides }\end{array}$ & $\begin{array}{l}\text { Chinese, } \\
404 \text { sides }\end{array}$ & $\begin{array}{l}\text { Korean, } \\
114 \text { sides }\end{array}$ & $\begin{array}{l}\text { Vietnam, } \\
208 \text { sides }\end{array}$ & $\begin{array}{l}\text { Caucasian, } \\
82 \text { sides }\end{array}$ \\
\hline SBFC, $n(\%)$ & $22(9.6)$ & $21(7.0)$ & $36(9.0)$ & $16(14.0)$ & $9(4.3)$ & $5(6.1)$ \\
SOEC, $n(\%)$ & $50(21.9)$ & $18(6.0)$ & $22(5.4)$ & $3(2.6)$ & $36(17.3)$ & $53(64.6)$ \\
\hline
\end{tabular}

SOEC, supraorbital ethmoid cell; SBFC, supra bulla frontal cell.

these 2 types of cells are as follows: (1) the SBFC does not pneumatize above the orbit, but the SOEC pneumatizes above the orbit and (2) every SBFC obstructs the drainage pathway of the frontal sinus, but not every SOEC obstructs the drainage pathway. Although the SOEC can also extend into the frontal sinus, not every SOEC encroaches into the frontal sinus [18]. In our study, of the 50 sides with SOECs, the cell entered into the frontal sinus in 32 sides, while it did not enter in 18 sides. If the SOEC extends into the frontal sinus, then surgery becomes more challenging.

Anterosuperior Portion of Bulla Lamella in Frontal Sinusotomy
Loury [19] and Ji et al. [20] have proposed a surgical approach to the frontal sinus via the route anterior to the ethmoid bulla and described a method of frontal recess dissection in which the ethmoidal bulla remains intact. The procedure was performed anterior to the ethmoid bulla lamella, and the lamella was complete in most patients. The advantage of the intact bulla lamella approach is that it can prevent damage to the anterior ethmoid artery and provide an ideal landmark for the posterior margin of the frontal ostium. However, in patients with SBFC and SOEC, the second lamella enters into the frontal sinus and the frontal 
sinus drainage pathway will be obstructed by these cells. Therefore, this anterior bulla approach is not suitable for managing CRS patients with SBFC and SOEC.

During endoscopic frontal sinusotomy, we agree with Wormald's [21] "all or nothing strategy," which means either the entire frontal recess is left alone or all the cells are removed from the recess. By creating a patent frontal sinus outflow tract, the ventilation and drainage of the frontal sinus can be improved, and the local drug can be easily delivered to the frontal sinus [22]. So total dissection of all frontal recess cells is necessary to ensure a patent frontal ostium. As early as 2001, Kim et al. [23] have proposed the importance of the bulla lamella and suggested that removing the upper portion of the bulla lamella to get a patent frontal ostium was safe and easy. In this study, in patients with SBFC or SOEC, the anterosuperior portion of the bulla lamella can extend into the frontal sinus, and sometimes, the lamella can almost reach the roof of the frontal sinus. Hence, thorough dissection of the most anterosuperior part of the lamella can be a challenge to surgeons. Some special instruments and techniques are needed for the procedure. We preferred to use a thin suction tip, curved curette and seeker, giraffe forceps, angled Medtronic blades, and Stylus high-speed drill. Even with the help of these tools, the time to completion of the frontal sinusotomy and the difficulty of the operation will be greater than those in cases without these cells [24]. For refractory CRS patients with asthma, especially for the revision surgery, if the anterosuperior portion of the bulla lamella cannot be addressed properly, then a Draf III procedure can be performed to deal with the frontal sinus.

One of the limitations of the study is that we only investigated patients with CRS and did not compare these patients with healthy controls. The reliability of the results may be an issue. Besides, all the patients were Chinese, and thus, extrapolating the results to different ethnicities may be variable. In the future, subpopulations such as healthy controls, primary and revision CRS cases, and subjects of different ethnicities will be included.

\section{Conclusion}

There was an association between the presence of SBFC and the occurrence of FS. Extension of the anterosuperior portion of the bulla lamella into the frontal sinus obstructs the drainage pathway posteriorly. Surgeons can seek the frontal sinus drainage pathway anteriorly.
Understanding the anatomy of the anterosuperior portion of the bulla lamella may help surgeons in performing frontal sinusotomy to obtain a patent frontal ostium. Angled instruments are useful in dissecting the bulla lamella.

\section{Acknowledgements}

We are grateful to Prof. P.J. Wormald for providing writing assistance and Prof. Li-Rong Liang for assisting us in the statistical analysis.

\section{Statement of Ethics}

The study was approved by the Ethics Committee of Peking University (2016HB209-1) and was performed in accordance with the principles stated in the Declaration of Helsinki. All subjects provided written informed consent after acknowledging full understanding of the study.

\section{Conflict of Interest Statement}

The authors have no conflicts of interest to declare.

\section{Funding Sources}

The Capital Health Development Foundation (No.: 2020-12051), the Capital Health Development Foundation (No.: 2016-12052) and the Research and Development Foundation of the Peking University People' Hospital (RDC-2015-03) supported this study.

\section{Author Contributions}

Muhan Shi was involved in study conception, data acquisition, statistical analysis; interpretation, and drafting and revision of the manuscript. Yuxiao Wu and Yuguang Wang: data acquisition; interpretation, drafting, and revision. Min Wang was involved in study conception, data acquisition, statistical analysis, drafting, revision, and final approval of the manuscript. Fei Yuan and Zhimin Xing conducted data acquisition and manuscript revision. Hui Li and Shien Huang participated in data acquisition and interpretation.

\section{Data Availability Statement}

The data that support the findings of this study are not publicly available due to their containing information that could compromise the privacy of research participants but are available from the corresponding author upon reasonable requests. 


\section{References}

1 Fokkens WJ, Lund VJ, Hopkins C, Hellings PW, Kern R, Reitsma S, et al. European position paper on rhinosinusitis and nasal polyps 2020. Rhinology. 2020;58:1-464.

2 Wang M, Yuan F, Qi WW, Cheng JY, Yuan XP, Han L, et al. Anatomy, classification of intersinus septal cell and its clinical significance in frontal sinus endoscopic surgery in Chinese subjects. Chin Med J. 2012;125: 4470-3.

3 Rathor A, Bhattacharjee A. Clinical-radiological correlation and role of computed tomography staging in chronic rhinosinusitis. World J Otorhinolaryngol Head Neck Surg. 2017;3(3):169-75.

4 Kubota K, Takeno S, Hirakawa K. Frontal recess anatomy in Japanese subjects and its effect on the development of frontal sinusitis: computed tomography analysis. J Otolaryngol Head Neck Surg. 2015;44(1):21.

5 Johari HH, Mohamad I, Sachlin IS, Aziz ME, Mey TY, Ramli RR, et al. A computed tomographic analysis of frontal recess cells in association with the development of frontal sinusitis. Auris Nasus Larynx. 2018;45:1183-90.

6 Wormald PJ, Hoseman W, Callejas C, Weber RK, Kennedy DW, Citardi MJ, et al. The international frontal sinus anatomy classification (IFAC) and classification of the extent of endoscopic frontal sinus surgery (EFSS). Int Forum Allergy Rhinol. 2016;6:677-96.

7 Tan KL, Lee WH, Kim JW. Classification of suprabullar pneumatization according to the skull base attachment of the second lamella. Eur Arch Otorhinolaryngol. 2017;274:223-9.

8 Lee WT, Kuhn FA, Citardi MJ. 3D computed tomographic analysis of frontal recess anatomy in patients without frontal sinusitis. Otolaryngol Head Neck Surg. 2004;131:164-73.
9 Kuhn FA. Chronic frontal sinusitis: the endoscopic frontal recess approach. Oper Tech Otolaryngol Head Neck Surg. 1996;7(3):2229.

10 Angelico FV, Rapoport PB. Analysis of the agger nasi cell and frontal sinus ostium sizes using computed tomography of the paranasal sinuses. Braz J Otorhinolaryngol. 2013;79: 285-92.

11 Liu SC, Wang CH, Wang HW. Prevalence of the uncinate process, agger nasi cell and their relationship in a Taiwanese population. Rhinology. 2010;48:239-44.

12 Park SS, Yoon BN, Cho KS, Roh HJ. Pneumatization pattern of the frontal recess: relationship of the anterior-to-posterior length of frontal isthmus and/or frontal recess with the volume of agger nasi cell. Clin Exp Otorhinolaryngol. 2010;3(2):76-83.

13 Joshi AA, Shah KD, Bradoo RA. Radiological correlation between the anterior ethmoidal artery and the supraorbital ethmoid cell. Indian J Otolaryngol Head Neck Surg. 2010;62: 299-303.

14 Zhang L, Han D, Ge W, Tao J, Wang X, Li Y, et al. Computed tomographic and endoscopic analysis of supraorbital ethmoid cells. Otolaryngol Head Neck Surg. 2007;137:562-8.

15 Cho JH, Citardi MJ, Lee WT, Sautter NB, Lee $\mathrm{HM}$, Yoon JH, et al. Comparison of frontal pneumatization patterns between Koreans and Caucasians. Otolaryngol Head Neck Surg. 2006;135:780-6.

16 Han D, Zhang L, Ge W, Tao J, Xian J, Zhou B. Multiplanar computed tomographic analysis of the frontal recess region in Chinese subjects without frontal sinus disease symptoms. ORL J Otorhinolaryngol Relat Spec. 2008;70:10412.
17 Tran LV, Ngo NH, Psaltis AJ. A radiological study assessing the prevalence of frontal recess cells and the most common frontal sinus drainage pathways. Am J Rhinol Allergy. 2019;33(3):323-30.

18 Thomas L, Pallanch JF. Three-dimensional CT reconstruction and virtual endoscopic study of the ostial orientations of the frontal recess. Am J Rhinol Allergy. 2010;24(5):37884.

19 Loury MC. Endoscopic frontal recess and frontal sinus ostium dissection. Laryngoscope. 1993;103:455-8

20 Ji J, Zhou M, Li Z, Wang T, Cheng Y, Wang Q. Frontal sinus surgery anterior to the ethmoid bulla. Int Surg. 2013;98:149-55.

21 Wormald PJ. Surgical approach to the frontal sinus and frontal recess. Endoscopic sinus surgery: anatomy, three-dimensional reconstruction, and surgical technique. 4 th ed. New York: Thieme; 2018. p. 89-111.

22 Wu YX, Wang M, Li H, Xing ZM, Shi MH, Huang SE, et al. Efficacy and safety of delivery of topical medication on to the frontal sinus at different head positions after frontal sinusotomy. Eur Arch Otorhinolaryngol. 2020; 277(5):1361-8

23 Kim KS, Kim HU, Chung IH, Lee JG, Park IY, Yoon JH. Surgical anatomy of the nasofrontal duct: anatomical and computed tomographic analysis. Laryngoscope. 2001;111:603-8.

24 Chen PG, Levy JM, Choby G, Smith K, Yao WC, Halderman A, et al. Characterizing the complexity of frontal endoscopic sinus surgery: a multi-institutional, prospective, observational trial. Int Forum Allergy Rhinol. 2021;11(5):941-5. 